\title{
A multi-sectoral version of the Post-Keynesian growth model ${ }^{\star}$
}

\author{
Ricardo Azevedo Araujo \\ Professor - Universidade de Brasília (UnB) - Departamento de Economia \\ Endereço: Campus Universitário Darcy Ribeiro - Prédio da FACE - Brasília/DF - Brasil \\ CEP: 70910-900 - E-mail: rsaaraujo@unb.br
}

Joanílio Rodolpho Teixeira

Professor - Universidade de Brasília (UnB) - Departamento de Economia

Endereço: Campus Universitário Darcy Ribeiro - Prédio da FACE Brasília/DF - Brasil

CEP: 70910-900 - E-mail: jaonilioteixeira@hotmail.com

Recebido em 08 de janeiro de 2013. Aceito em 01 de julho de 2014.

\begin{abstract}
With this inquiry, we seek to develop a disaggregated version of the post-Keynesian approach to economic growth, by showing that indeed it can be treated as a particular case of the Pasinettian model of structural change and economic expansion. By relying upon vertical integration it becomes possible to carry out the analysis initiated by Kaldor (1956) and Robinson (1956, 1962), and followed by Dutt (1984), Rowthorn (1982) and later Bhaduri and Marglin (1990) in a multi-sectoral model in which demand and productivity increase at different paces in each sector. By adopting this approach it is possible to show that the structural economic dynamics is conditioned not only to patterns of evolving demand and diffusion of technological progress but also to the distributive features of the economy, which can give rise to different regimes of economic growth. Besides, we find it possible to determine the natural rate of profit that makes the mark-up rate to be constant over time.
\end{abstract}

\section{Keywords}

Post-Keynesian growth model. Structural change. Multi-sector models.

\section{Resumo}

Neste artigo, pretende-se desenvolver uma versão desagregada da abordagem pós-Keynesiana para o crescimento econômico, mostrando que de fato esse modelo pode ser tratado como um caso particular do modelo Pasinettiano de mudança estrutural e crescimento econômico. Utilizando-se o conceito de integração vertical, torna-se possível conduzir a análise iniciada por Kaldor (1956) e Robinson (1956, 1962), e seguido por Dutt (1984), Rowthorn (1982) e, posteriormente, Bhaduri e Marglin (1990) em um modelo multi-sectorial em que há aumentos da demanda e produtividade em ritmos diferentes em cada setor. Ao adotar essa abordagem, é possível mostrar que a dinâmica de mudança estrutural está condicionada não apenas aos padrões de deman-

- A preliminary version of this paper was presented in the VIII International Colloquium on Economic Growth, Structural Change and Institutions held in Galway, Ireland, May 26-28, 2011. We would like to thank the participants of the colloquium and an anonymous referee for helpful comments. The usual disclaimer applies. 
da de evolução das preferências e da difusão do progresso tecnológico, mas também com as características distributivas da economia, que podem dar origem a diferentes regimes setoriais de crescimento econômico. Além disso, é possível determinar a taxa natural de lucro que faz com que a taxa de mark-up seja constante ao longo do tempo.

\section{Palavras-Chave}

Modelo Pós-Keynesiano de crescimento econômico. Mudança estrutural. Modelos multi-setoriais.

\section{JEL Classification}

E21, O11.

\section{Introduction}

It is not easy to define what the Post-Keynesian growth model PKGM hereafter - is as long as there are a number of models in this tradition with different assumptions, focuses and results, some of them contradictory. ${ }^{1}$ But in general this terminology is adopted to designate the growth model that was initially coined by Kaldor (1956) and Robinson (1956, 1962) and extended by Dutt (1984), Rowthorn (1982) as well as by Bhaduri and Marglin (1990). Integral to its evolution the PKGM passes through three principal phases that are labeled as 'generations'. Although Kaldor (1956) has built his seminal model on the notion of full capacity utilization, Dutt (1984) and Rowthorn (1982), working independently, have built what is known as the second generation of the PKGM by endogenizing the rate of capacity utilization in the lines of Steindl (1952). One of the main contributions of this generation is the possibility of disequilibrium and the presence of a stagnationist regime in which an increase in the profit share implies a reduction in capacity utilization. The key assumption behind this result is that the growth rate of investment is a function not only of the profit rate, as in Kaldor-Robinson but also of the rate of capacity utilization.

Bhaduri and Marglin (1990) have challenged this view by considering that the growth rate of investment is a straight function not of the profit rate but of the profit share. According to them the profit rate should be replaced by the margin of profit conveyed by the profit share in the investment equation. One of the properties of the third generation model, as it became known, is the possibility of a

\footnotetext{
1 See Stockhammer (1999) for a survey of the PKGM.
} 
non-stagnationist regime in which eventual falls in consumption due to a lower real wage are overcompensated by an increase in investment led by a profit share expansion.

Although the PKGM shares some common characteristics with other models in the heterodox view it is subject to the same criticism highlighted by Pasinetti (2005, p. 839-40) to explain why the Keynesian School has somewhat failed as a successful alternative paradigm to mainstream economics. ${ }^{2}$ He points out a lack of theoretical cohesion amongst models in this tradition. In this paper we intend to contribute to fill this gap by building a bridge between the Pasinetti's model of Structural Change and Economic Growth and the PKGM.

Although sharing the Cambridge's heritage these models belong to different strands of the literature. The Pasinettian model is neoRicardian in essence with strong connections with the Sraffian framework and the PKGM has deep influences of the seminal work of Kalecki. While the former focuses mainly on determination of economic growth from the interaction between technical progress and evolution of demand patterns the latter focuses on this issue from a point of view of class struggle, which allows it to consider the existence of different regimes of economic dynamics. Intending to build a reconciliation between the Kaleckian effective demand and Sraffian normal prices Lavoie (2003, p. 53) considers that "a large range of agreement has remained, in particular about a most crucial issue, the causal role played by effective demand in the theory of capital accumulation". Besides, both approaches are built on the notion of vertical integration ${ }^{3}$ and consider a simultaneous supply and demand determination of economic growth with disequilibria as an inevitable outcome of economic growth.

2 Of course some effort was made in order to establish connections among these approaches. The works of Trigg and Lee (2005), Araujo and Teixeira (2002) and Araujo and Lima (2007) trying to connect the Pasinetti's analysis with Keynes, Feldman and Thirlwall's models respectively are just some examples of this pursue but substantive work remains to be done.

3 Steedman (1992) argues that vertical integration is very useful in some fields of economic analysis but Kaleckian mark-up pricing theory is not one of them. Here we dispute this view by showing that the PKGM may be treated as a particular case of the Pasinetti's model that is also built on the notion of vertical integration. One of the key differences between these approaches is the level in which the analysis of vertical integration is carried on. While in the later the model is disaggregated the former aggregates the whole economy in one sector. 
However, a key methodological difference between the two approaches remains: the PKGM consider national economies in the aggregate. ${ }^{4}$ It is worth to remember that one of the major criticisms PostKeynesians leveled against the Neoclassical model is that it aggregates the whole economy into one sector, rendering the model incapable of performing an analysis of structural change. Furthermore, implicit in the Neoclassical representation is a well-known and strict definition of balanced growth, assuming that growth is non-inflationary with full-capacity utilisation.

This view precludes any analysis of the relationship between growth and inequality. In his challenge to the Neoclassical model, Ocampo (2005, p. 8) considers that: "[t]he contrast between the balloon and structural dynamics views of economic growth can be understood in terms of the interpretation of one of the regularities identified in the growth literature". We interpret that Ocampo is referring to the tendency of per capita GDP growth to be accompanied by regular changes in the sectoral composition of output. According to the balloon view, these structural changes are simply a by-product of the growth in per capita GDP. In the alternative reading, success in structural change proves to be the key to economic development.

In order to overcome this limitation of the PKGM here its analysis is performed in a multi-sector framework by treating them as a particular case of the Pasinetti's model (1981, 1993). Another gain that accrues from considering the PKGM as a particular case of Pasinetti's model is that the latter includes the derivation of normal prices and natural rate of profits. According to Sebastiani (1989, $\mathrm{p}$ xiv), "the need to complete the Kaleckian scheme with a theory of the rate of profit and of normal prices is made even more urgent by the necessity to confront the problem of normal productive capacity and that of choice of techniques". This view is confirmed by Nell (1989, p. 163) who considers that "Kalecki's approach implicitly rests on the relationship between the rate of profit and normal prices, and to be complete requires a theory of the determinants of the rate of profits". Following our approach it is also possible to derive

${ }^{4}$ In fact in his analysis Kalecki $(1954,1968)$ considers an economy with three compartments that can be viewed as a first approximation to a multisectoral analysis. Besides, his digression on mark-ups relies implicitly on reasoning that accrues from a multissectoral viewpoint since he considers crucial the comparison between sectoral and average mark-ups. It is important to emphasize that he already in the 1930's had considered pricing, distribution, employment and the cycle as being simultaneously determined.

Estud. Econ., São Paulo, vol.45, n.1, p. 127-152, jan.-mar. 2015 
a natural rate of profit that makes the mark-up rate to be constant over time [see Taylor (1985, p. 284)]. Besides from a Pasinettian reading of the PKGM we show that the existence of excess capacity is not inconsistent with long-run equilibrium as argued by some authors such as Eatwell (1983).

With this analysis we also intend to provide answer for one of the questions raised by Steedman (1992). According to him, it is important to explain why vertical integration is adopted in Kaleckian models when forces and factors that explain the magnitudes of mark-ups have meanings at the level of real, actual industries. This view emphasizes the role of competition amongst firms and not amongst sectors in the determination of mark-up. Here we show that although vertical integration is an analytical device with difficult meaning to grasp from an empirical viewpoint, it is possible to particularize mark-ups to vertically integrated sectors. Furthermore, by adopting this approach we are able to escape from another weakness of Kalecki's work mainly associated with the difficulty of defining precisely an industry as pointed out by Harcourt (1987, p. xi).

This article is structured as follows. In the next section we provide a systematic presentation of the generations of the PKGM. In section 3 we treat these versions as particular cases of the Pasinettian model of structural change by using the device of vertical integration. In section 4 we show that the properties of natural growing system as defined by Pasinetti allows us to established the savings propensities that generate full employment. In section 5 we conclude.

\section{The Post-Keynesian growth model}

An important characteristic of the PKGM is the existence of independent investment and savings functions that depends on income distribution. The saving propensities, for instance, are particular to each class may it be workers or capitalists. Unlike the Neoclassical model, the PKGM considers that neither savings nor technological progress is the variable that drives the growth process. The rationale is that investment is determined essentially by the availability of credit in the financial sector as well as the 'animal spirits'. 
Once investment is made effective demand determines output which in turns determines savings.

The main assumptions behind the PKGM are noted: the economy is closed and produces only one good that can be both a consumption as well as a capital good. Technology is characterized by fixed coefficients. Likewise, there are constant returns to scale. There is no government, and the monetary side is ignored. All firms are equal in the sense that they wield no differences in market power. In such an economy, the value of net aggregate output is equal to the sum of the wages and profits, namely:

$$
p X=w N+r p K
$$

Where $p$ is the price level, $X$ is the level of real output, $w$ is the nominal wage rate, $N$ is the level of labour employment, $r$ is the rate of profit and $K$ is the stock of capital. Expression (1) may be rewritten as:

$$
p=w \frac{N}{X}+r p \frac{K}{X}
$$

Now define $l=\frac{N}{X}$ as the labour per unit of output, $v=\frac{K}{X_{f e}}$ as the capital-output ratio and $u=\frac{X}{X_{f e}}$ as the rate of capacity utilization, where $X_{f e}$ stands for the full employment output. By using this nota tion $\frac{K}{X}=\frac{v}{u}$ and assuming that $v$ is constant and normalized to one we can rewrite expression (1)' as:

$$
p=w l+r p u^{-1}
$$

Let us assume that prices are given by a mark-up rule over wage according to:

$$
p=(1+\tau) w l
$$

Where $\tau$ is the mark-up rate. By substituting expression (2) into (1)", simple algebraic manipulation allows us to obtain the following relationship between the profit share, the rate of profit and the rate of capacity utilization: 


$$
r=\pi u
$$

Implicit in this result is the fact that the profit share is given by: $\pi=\frac{\tau}{(1+\tau)}$. Expression (3) gives us the profit rate from the supply side of the model. In order to find the profit rate from the demand side let us consider separately the contribution of some authors in order to emphasize the evolution of the model.

\subsection{First generation [Kaldor (1956) and Robinson (1956, 1962)]}

The first generation model draws from Kaldor (1956) and Robinson (1956, 1962). There are some differences between the approaches developed by these authors; however, the core of their models may be described as follows. It is assumed that workers do not save and that the economy operates at full capacity, ${ }^{5}$ which means that $u=1$. The growth rate of investment, $g_{I}$, is assumed to be given by:

$$
g_{I}=g_{o}+\alpha r
$$

Where $\alpha>0$ measures the influence of the investment to the profit rate, $r$, and $g_{o}>0$ stands for the growth rate of autonomous investment. The positive effect of the rate of profit on investment decisions relies on the relation between actual and expected profits. The growth rate of savings, $g_{s}$, is given by the Cambridge equation:

$$
g_{S}=s r
$$

Where $s$ is the saving propensity, with $0 \leq s \leq 1$. Note that equation (5) does not determine the rate of profit as in the Kaldor-Pasinetti process where the natural growth rate is given, and determines the rate of profit once the propensity to save is exogenous [See Araujo (1992-93)]. In the PKGM the natural rate of growth is also endogenous and hence expression (5) has two unknowns. In order to determine the rate of profit it is necessary to equalize (4) to (5) which yields:

$$
r^{*}=\frac{g_{o}}{s-\alpha}
$$

5 Robinson $(1956,1962)$ refers to a 'normal' rate of capacity utilization to express that degree of utilization of productive capacity that producers consider as ideally suited to fulfill demand requirements. 
It is required that $s>\alpha$ to generate a positive rate of profit, which means that the responsiveness of the savings to the profit rate has to be larger than the responsiveness of the investment. Expression (6) yields an inverse relationship between the rate of profit and the saving rate, namely:

$$
\frac{\partial r^{*}}{\partial s}=-\frac{g_{o}}{(s-\alpha)^{2}}<0
$$

By replacing (6) into Expression (4) or (5) we conclude that the balanced growth rate is given by:

$$
g^{*}=\frac{s g_{o}}{s-\alpha}
$$

From Expression (7) we also obtain an inverse relationship between the growth rate and the saving rate:

$$
\frac{\partial g^{*}}{\partial s}=-\frac{g_{o} \alpha}{(s-\alpha)^{2}}<0
$$

Expression (7)' shows that higher saving propensity imply both lower growth rates as well as lower levels of profitability. These results may be understood by considering that higher saving propensity implies lower consumer propensity which means smaller aggregate demand.

2.2. Second generation: the Neo-Kaleckian model [Dutt (1984) and Rowthorn (1982)]

Capacity utilization is now depicted as an endogenous variable that can be different from full capacity utilization. Such view gives rise to the main difference in relation to the first generation model, namely: the variable that measures capacity utilization enters the equation of growth rate of investment, meaning that the higher the 
rate of capacity utilization the higher the growth rate of investment [Steindl (1952)]:

$$
g_{I}=g_{o}+\alpha r+\beta u
$$

Where $\beta>0$ measures the sensibility of the growth rate of investment to the capacity utilization and captures the accelerator effect: a high rate of capacity utilization induces firms to expand capacity in order to meet anticipated demand while low utilization induces firms to contract investment. The growth rate of savings is also given by the Cambridge Equation (5) in which workers are not noted to save. The system formed by Expressions (3), (5) and (8) contains three unknowns, namely $r, u$ and $g$. By inserting Expression (3) into Expression (8) and equalizing this latter expression to Expression (5) yields the rate of capacity utilization:

$$
u^{*}=\frac{g_{o}}{\pi(s-\alpha)-\beta}
$$

Note that the effect of a variation in the profit share to the capacity utilization is:

$$
\frac{\partial u^{*}}{\partial \pi}=-\frac{s-\alpha}{[\pi(s-\alpha)-\beta]^{2}}<0
$$

A rationale for this result may be grasped considering that in this set up the marginal propensity to consume of workers is larger than that of capitalists. In this vein an increase in the profit share decreases aggregate demand and capacity utilization. By replacing Expression (9) into relation (3) we obtain the rate of profit:

$$
r^{*}=\frac{\pi g_{o}}{\pi(s-\alpha)-\beta}
$$

Taking the derivative of Expression (10) in relation to the profit share, $\pi$, one obtains:

$$
\frac{\partial r^{*}}{\partial \pi}=-\frac{g_{o} \beta}{[\pi(s-\alpha)-\beta]^{2}}<0
$$


This result indicates that a redistribution of income towards wages may yield a higher rate of capacity utilization, as shown by Blecker (1989). By inserting Expression (9) and (10) into Expression (8) yields the balanced growth rate:

$$
g^{*}=\frac{s \pi g_{o}}{\pi(s-\alpha)-\beta}
$$

Taking the derivative of Expression (11) in relation to the profit share, $\pi$, one obtains:

$$
\frac{\partial g^{*}}{\partial \pi}=-\frac{s \beta g_{o}}{[\pi(s-\alpha)-\beta]^{2}}<0
$$

According to Expression (11)', the higher the profit-share the smaller the balanced growth rate. This result may be understood in terms of a smaller propensity of consuming by capitalists which leads to a smaller aggregate demand.

\subsection{Third generation: Bhaduri and Marglin (1990)}

The investment function now reacts positively to profits and capacity utilization, given that the profit-share is used as a measure of profitability:

$$
g_{I}=h(\pi, u)
$$

With partial derivatives $h_{\pi}(\pi, u)>0$ and $h_{u}(\pi, u)>0$. According to Bhaduri and Marglin (1990, p. 380), influences of existing capacity on investment cannot be captured satisfactorily by simply introducing a term for capacity utilization. The investment function should also consider profit share and capacity utilization as independent and separate variables in the lines of Expression (12). Following Blecker

\footnotetext{
6 Note that there is no reason to assure that this balanced growth rate is equal to either the warranted growth rate, or the natural growth rate. However as pointed out by Harcourt (2010, p. 479) in his comment to the work of John Cornwall, "the assumption of the independence of the factors responsible for the expected $\left(g_{e}\right)$, warranted $\left(g_{w}\right)$ and actual rates of growth $\left(g_{a}\right)$ from those responsible for the natural rate of growth $\left(g_{n}\right)$ was inadmissible. Basically, the determinants of the components of $g_{n}$ - the rate of growth of the workforce and its improvement—cannot be independent of those that determined the demand side of an economy's performance."
} 
(2002, p. 137) let us assume for the sake of convenience only a linear investment function:

$$
g_{I}=g_{o}+\alpha \pi+\beta u
$$

The growth rate of savings is given by the Cambridge Equation. By inserting expression (3) into Expression (5) and equalizing the latter to Expression (12)' yields the rate of capacity utilization:

$$
u^{*}=\frac{g_{o}+\alpha \pi}{s \pi-\beta}
$$

Note that a necessary condition for a positive rate of capacity utilization is: $s \pi>\beta$. From Expression (13) it is possible to conclude that:

$$
\frac{\partial u^{*}}{\partial \pi}=-\frac{g_{o} s+\alpha \pi}{(s \pi-\beta)^{2}}<0
$$

An increase in the profit share would indeed decrease capacity utilization. The rate of profit may be obtained by substituting Expression (13) into Expression (3):

$$
r^{*}=\frac{\pi\left(g_{o}+\alpha \pi\right)}{s \pi-\beta}
$$

The main difference in the results of the Bhaduri-Marglin (1990) and the neo-Kaleckian approach is that in the former, the derivative of the profit rate in relation to the profit share may be positive or negative as follows by the differentiation of Expression (14) in relation to $\pi$ :

$$
\frac{\partial r^{*}}{\partial \pi}=-\frac{\alpha \pi-\beta u^{*}}{s \pi-\beta}<o r>0
$$

Now there may be a positive capacity effect and a negative profit share effect on investment. Thus, two regimes are possible, depending on the relative magnitudes of capacity utilization and profit share effects in the investment function. If the profit effect is stronger than the capacity effect, meaning that $\alpha \pi-\beta u^{*}>0$, growth is wage-led. Otherwise, if $\alpha \pi-\beta u^{*}>0$, growth is profit-led. The 
balanced growth rate of the economy is then obtained by replacing expression (13) into expression (12) which yields:

$$
g^{*}=\frac{s \pi\left(g_{o}+\alpha \pi\right)}{s \pi-\beta}
$$

Taking the derivative of Expression (15) in relation to the profit share, $\pi$, one obtains:

$$
\frac{\partial g^{*}}{\partial \pi}=-\frac{s\left(\alpha \pi-\beta u^{*}\right)}{s \pi-\beta}<\text { or }>0
$$

Possibilities now arise that an increase in the profit share will lead to a higher rate of balanced growth path. This happens if the economy operates under a profit-led regime.

\section{A Multi-Sector version of the PKGM}

The main focus of the Pasinettian approach is on the structural economic dynamics but his analysis includes also a macroeconomic determination of economic growth. ${ }^{7}$ His analysis is carried out, not in terms of input-output relations, as has become usual in multi-sector models, but rather in terms of vertically integrated sectors. This device is used to focus on final commodities rather than on industries. In this case, it is possible to associate each commodity to its final inputs - a flow of working services and a stock of capital goods - thus eliminating all intermediate inputs. From this point of view, such framework may be adopted to approach the PKGM although the latter does not consider the distinction between capital and consumption goods: only one commodity is produced. This view is also supported by Bhaduri and Marglin (1990, p.377) for whom in the PKGM "we can think of the representative firm as vertically integrated using directly and indirectly a constant amount of labour per unit of final output."

7 Trigg and Lee (2005) for instance explore the relation between the Keynesian multiplier and Pasinetti's model of pure production to derive the Keynes's multiplier from multi-sectoral foundations. 
Hence, the starting point of the present analysis is to consider that the Post-Keynesian structure is a vertically integrated model in which this device was used to its limit. As pointed out by Lavoie (1997, p. 453), "the concept of vertical integration, although extensively but implicitly used in macroeconomic analysis, has always been difficult to seize intuitively". What is behind this affirmation is that models that are aggregated in one or two sector are based on the device of vertical integration. This range of vision is confirmed by Scazzieri (1990, p.26) for whom "[a]ny given economic system may generally be partitioned into a number of distinct subsystems, which may be identified according to a variety of criteria. However, the utilization of subsystems for the analysis of structural change is often associated with the consideration of subsystems of a particular type. These are subsets of economic relationships that may be identified by the logical device of vertical integration (...)". Hence it is possible to view the PKGM as a vertically integrated model because it has the same characteristics of what Sraffa (1960, appendix A) has called sub-systems - i.e. it is self-reproducible, it uses no intermediate goods to produce only a single commodity. ${ }^{8}$

This view is confirmed by Steedman (1992, p. 136) for whom "Kaleckian writings frequently appeal to vertically integrated representations of the economy." But we do not fully agree with his view when he considers that vertical integration is not suited to discuss Kaleckian issues such as concentration and selling costs. In our viewpoint the problem related to the use of vertical integration in Kaleckian models is related to the fact that this device is used to its extreme giving rise to an economy aggregated in one sector that does not allow performing a proper analysis of some important issues related to the structural economic dynamics. Here we consider that a multi-sectoral version of the PKGM could highlight some sectoral issues that can be dealt with only in a disaggregated set up but avoiding cumbersome inter-industrial relations.

\footnotetext{
8 Araujo and Teixeira (2002) has adopted this idea to show that the Feldman's bi-sectoral model of economic growth may also be considered a vertically integrated model in each this technique was adopted to produce a two-sector model. In fact the concept of vertical integration has been widely used in macroeconomics.
} 
A possible departing point to establish a bridge between the two approaches is to consider the relationship $r=\pi u$ in a sectoral environment. This is an important point since although vertically integrated 'industries' are merely weighted combinations of real industries [Steedman (1992, p. 149)] it is possible to particularize to each sector a profit share, a rate of capacity utilization and a rate of profit, and to establish a relation among these variables in a multisectoral economy.

The economy is assumed to produce $n-1$ consumption goods: one in each vertically integrated sector ${ }^{9}$ but with different patterns of production and consumption. Corresponding to each consumption goods sector there is a specific capital goods sector ${ }^{10}$. Let us consider that $X_{i}$ denotes the physical quantity produced of consumption good $i, X_{k_{i}}$ the physical quantity produced of capital goods $k_{i}$, and $X_{n}$ represents the quantity of labour in all internal production activities. According to this notation, note that $X_{n}=N$. Per capita demand of consumption goods is represented by a set of consumption coeffi cients $a_{i n}=\frac{x_{i n}}{X_{n}}$, where $x_{i n}$ stands for the demand for consumption good $i$. In the same vein, $a_{k_{i}, n}$ stand for the investment coefficients of capital goods $k_{i}$. The production coefficients of consumption and capital goods are respectively $a_{n i}$ and $a_{n k_{i}}$. The family sector is denoted by $n$. The physical system may be written as follows:

$$
\begin{cases}X_{i}-a_{i n} X_{n}=0, & i=1, \ldots, n-1 \\ X_{k_{i}}-a_{k_{i}, n} X_{n}=0, & i=1, \ldots, n-1 \\ X_{n}-\sum_{i=1}^{n-1} a_{n i} X_{i}-\sum_{i=1}^{n-1} a_{n k_{i}} X_{k_{i}}=0 & \end{cases}
$$

According to this formulation, the first $n-1$ equations of the system denote equilibrium in the consumption goods sector, while the next $n-1$ equation express the equilibrium in the capital goods sectors. The last equation denotes equilibrium in the labour market. ${ }^{11}$

9 Halevi (1996, p. 194) argues that "the theory of growth based on vertical integration revolutionizes the very concept of choice of technique and by focusing on the per capita demand, it overcomes the limitations of Feldman's strategy of growth". See also Araujo \& Teixeira (2001a).

${ }^{10}$ For the sake of convenience only, we assume that capital goods do not depreciate and the production of capital goods requires only labour.

11 The system consists of $2(n-1)+1$ equations. 
A sufficient condition to ensure non-trivial solutions of the system for physical quantities is:

$$
\sum_{i=1}^{n-1} a_{i n} a_{n i}+a_{k_{i}, n} a_{n k_{i}}=1
$$

This is also a condition for full employment of the labour force. The equilibrium solution of the system for physical quantities is expressed as:

$$
\left\{\begin{array}{c}
X_{i}=a_{i n} X_{n} \\
X_{k_{i}}=a_{k_{i}, n} X_{n}
\end{array}\right.
$$

Considering that $p_{i}$ is the price of commodity $i(i=1,2, \ldots, n-1), p_{k_{i}}$ is the price of capital goods $k_{i}, r_{i}$ is the sectoral profit rate, and $w$ is the wage rate (uniform), the monetary system may be written as:

$$
\begin{cases}p_{i}-a_{n i} w-r_{i} p_{k_{i}}=0 & i=1, \ldots, n-1 \\ p_{k_{i}}-a_{n k_{i}} w=0 & i=1, \ldots, n-1 \\ w+\sum_{i=1}^{n-1}\left(a_{i n} p_{k_{i}} r_{i}-a_{i n} p_{i}-a_{k_{i}, n} p_{k_{i}}\right)=0\end{cases}
$$

System (19) is the monetary counterpart of system (16). According to this formulation, the first $n-1$ expression denote equilibrium in the $i$-th sector from a monetary viewpoint. The next $n-1$ expression have the same meaning in relation to the $k_{i}$ sectors. The last equation expresses the fact that the national income, composed of wages and profits, should be totally expended in either the consumption or the investment sectors ${ }^{12}$. The set of solution for prices may be expressed as:

$$
\left\{\begin{array}{c}
p_{i}=\left(a_{n i}+r_{i} a_{n k_{i}}\right) w \\
p_{k_{i}}=a_{n k_{i}} w
\end{array}\right.
$$

In general, if the rates of profit, $r_{i}(i=1, \ldots, n-1)$, are positive and the capital intensity is different from one production process to another, relative prices of consumption goods will depend both on labour

12 The system consists of $2(n-1)+1$ equations. 
inputs and on the rate of profit. Note that although the Pasinettian model is built in terms of vertically integrated sectors the price of the consumption goods may be given by a mark-up rule according to:

$$
p_{i}=\left(1+\tau_{i}\right) a_{n i} w
$$

Where $\tau_{i}$ is the mark-up rate for sector $i$. Note from the first expression of system (19) that in equilibrium:

$$
X_{i} p_{i}-a_{n i} w X_{i}=r_{i} p_{k_{i}} K_{i}
$$

where the right hand side is nothing but profits in the i-th sector, that is $\prod_{i}=r_{i} p_{k_{i}} K_{i}$. Therefore, expression (22) may be rewritten as:

$$
\prod_{i}=X_{i} p_{i}-a_{n i} X_{i} w
$$

By replacing the mark-up expression into expression (23) one obtains:

$\prod_{i}=X_{i}\left(p_{i}-a_{n i} w\right)=X_{i}\left[\left(1+\tau_{i}\right) a_{n i} w-a_{n i} w\right]=\tau_{i} a_{n i} w X_{i}$

The profit share in sector $i, \pi_{i}$, is then given by: $\pi_{i}=\frac{\prod_{i}}{p_{k_{i}} K_{i}}$. From Expression (24) and from the second line of Expression (20) we can rewrite the profit share in the $i$-th sector as:

$$
\pi_{i}=\frac{\prod_{i}}{p_{k_{i}} K_{i}}=\frac{\tau_{i} a_{n i} w X_{i}}{\left(1+\tau_{i}\right) a_{n i} w K_{i}}=\frac{\tau_{i}}{1+\tau_{i}}
$$

We are also using the fact that in equilibrium, which is an assumption behind expression (24), $K_{i}=X_{i}$, which makes the capital-out put ratio, namely $v_{i}=\frac{K_{i}}{X_{i}}$ equals to one. Assuming that $\frac{X_{i}}{K_{i}} \neq 1$ out of the equilibrium, and considering that $\prod_{i}=r_{i} p_{k_{i}} K_{i}$ one obtains by using (24) and (25) that:

$$
r_{i}=\frac{\prod_{i}}{p_{k_{i}} K_{i}}=\frac{\tau_{i} w a_{n i} X_{i}}{p_{k_{i}} K_{i}}=\frac{\tau_{i} w a_{n i} X_{i}}{w a_{n k_{i}} K_{i}}=\frac{\tau_{i}}{1+\tau_{i}} v_{i}^{-1} u_{i}
$$


Where $u_{i}=\frac{X_{i}}{X_{i}^{*}}$ is the rate of capacity utilization in the $i$-th sector, and $X_{i}^{*}$ is the equilibrium, or full capacity, output of the $i$-th sector. Expression (26) shows that the relationship $r=\pi u$ remains valid for a multi-sectoral economy in the case which $a_{n i}=\left(1+\tau_{i}\right) a_{n k_{i}}$ but now it has to take into account that $\pi_{i}$ is the sectoral profit share and $u_{i}$ is the sectoral rate of capacity utilization. ${ }^{13}$

The dynamic equilibrium of capital accumulation requires that $\dot{K}_{i}=\dot{X}_{i}$, where the dot stands for the time derivative. But we know from (18) that $X_{i}=a_{i n} X_{n}$ which implies that $\dot{X}_{i}=\left(\theta_{i}+g\right) X_{i}$ where $g$ is the growth rate of population and $\theta_{i}$ is the sectoral growth rate of demand, namely $\frac{\dot{a}_{i n}}{a_{i n}}=g$. Besides, the change in the stock of capital of $i$-th sector is given by the sectoral investment according to $\dot{K}_{i}=a_{k_{i}} X_{n}$. By equalizing these last expressions, we obtain: $a_{k_{i} n} X_{n}=\left(r_{i}+g\right) X_{i}$ which implies that $a_{k_{i} n}=\left(\theta_{i}+g\right) \frac{X_{i}}{X_{n}}$.

We can rewrite the latter formulae as:

$$
a_{k_{i} n}=\left(\theta_{i}+g\right) a_{i n}
$$

Equation (27) may be interpreted from two different viewpoints: on one hand it shows the level of investment that guarantees full capacity utilization through time. On the other hand it shows the level of investment in order to guarantee that the $i$-th sector will be endowed with the amount of capital goods necessary to produce the amount of final goods required by an increase in the labour force and per capita demand. If $a_{k, n}>\left(\theta_{i}+g\right) a_{i n}$ the $i$-th sector will face lack of capital utilization while if $a_{k_{i} n}<\left(\theta_{i}+g\right) a_{i n}$ the $i$-th sector will not be able to produce the amount of consumption goods that are required by consumer requirements.

In this vein the Pasinettian approach provides us with the concept of natural rate of profit, that is, a rate of profit that must be adopted in order to endow each sector with the capital goods required to allow

\footnotetext{
13 This result will be used later in order to establish a value of the mark-up rate related to the natural rate of profit.
} 
each sector to at least fulfil the demand requirements of that sector with no capacity excess. This rate is given by:

$$
r_{i}^{*}=g+\theta_{i}
$$

Note that if $r_{i}<g+\theta_{i}$ then capitalists in the $i$-th sector will not have the necessary amount of resources to invest in such sector in order to meet the expansion of demand. If $r_{i}>g+\theta_{i}$ then capitalist will overinvest in the $i$-th sector leading to excess of productive capacity.

As pointed out by Araujo and Teixeira (2003) the proportionality between the rate of profit to the sectoral rate of growth emerges as a natural requirement to endow the economic system with the necessary productive capacity to fulfil the expansion of demand. Therefore, a growing economy does imply a natural rate of profit, which is given by the Expression (28). In this vein the concept of 'natural rate of profit', introduced by Adam Smith (1776), is reinterpreted by Pasinetti $(1981,1988)$. Whereas the former argues that - due to the competition amongst capitalists - the ordinary rate of profit is - in the long run - uniform across sectors, Pasinetti (1981, p. 130) postulates that "there are as many natural rates of profit as there are rates of expansion of demand (and production) of the various consumption goods."

A possible interpretation of the disparity between the Pasinettian and Smithian concept of the 'natural rate of profit' is that the former is a warranted rate of profit that when adopted allows to endow each sector with the units of productive capacity necessary to fulfil demand requirements. The actual rate of profit does not necessarily lead to equilibrium in all sectors: some of them may operate with less capital goods than what is required and others may operate with excess of capacity utilization. However, it is important to stress the importance to establish a theory of natural prices in the Kaleckian framework. According to Nell (1989, p. 163), "Kalecki's theory of effective demand requires a theory of 'normal prices', independent of the short-period changes studied by that theory. These prices are required to establish the level of normal capacity utilisation and the realization of profits. Moreover the normal rate of profit is required in order to study the problem of the choice of technique." 
It is important to bear in mind that the Pasinettian model has a strong normative flavour, that is, it shows the requirements for an economic system to be in equilibrium but it does not say that this equilibrium will prevail.

\section{The assessment of the PKGM from a multi-sector viewpoint}

In terms of the present analysis it is then important to reconsider the meaning of expression (26). If we consider that along with Expression (28) Expression (26) gives us the notion of a natural rate of profit in a Pasinettian sense then it is necessary to consider that each sector will have its own rate of profit which is not the actual but the one that should the adopted in order to endow each sector with the units of productive capacity required to fulfil demand.

In this case we have to consider that each sector has its own rate of savings that is in fact a warranted saving rate that should be adopted in order to endow the sector with the capital goods necessary to meet the demand requirements in equilibrium. But, of course the saving rate is determined by the class, which in the present case, is the capitalist one and not by the sector. If we consider that each sector has its own rate of profit, given by the remuneration of capital necessary to fulfil demand requirements, then each sector will have a natural rate of saving; that is, a saving rate that should be practiced in order to endow that sector with the capital goods necessary to be in equilibrium.

This view is confirmed by Bellino (2010, p. 12) for whom "[i]n the natural configuration, 'profits' appear justified insofar as they are the source of financing investments, and as the income for some class, typically that of capitalists." By considering a multi-sector version of the PKGM, the sectoral growth rate of investment profit is given by the following table:

Table 1 - Sectoral Growth rate of investment

\begin{tabular}{|c|c|c|c|}
\hline & Kaldor-Robinson & Neo-Kaleckian & Bhaduri-Marglin \\
\hline $\begin{array}{c}\text { Sectoral Growth } \\
\text { rate of investment }\end{array}$ & $g_{I}^{i}=g_{o}+\alpha r_{i}$ & $g_{I}^{i}=g_{o}+\alpha r_{i}+\beta u_{i}$ & $g_{I}^{i}=g_{o}+\alpha \pi_{i}+\beta u_{i}$ \\
\hline
\end{tabular}


Note that the parameters of the model, namely $g_{o}, \alpha$ and $\beta$, are the same for all sectors, meaning that they are related inherently determined by the capitalist class irrespective of sectors. According to this formulation, the sectoral aspect of the model affects only the decisions to invest across sectors, which is captured by the sectoral variables $r_{i}, u_{i}$ and $\pi_{i}$. By considering that the Cambridge Equation provides the sectoral growth rate of savings for all generations, namely $g_{S}^{i}=s_{i} r_{i}$, it is possible to obtain the profit rate by equalizing the growth rate of investment and savings. For the second and third generations, it is also necessary to take into account that $r_{i}=\pi_{i} u_{i}$ to close the model, since $u_{i}$, namely the rate of capacity utilization in the $i$-th sector, enters the sectoral growth rate of investment for both models. After some algebraic manipulation, it is possible to show that the sectoral rate of profit for each generation is given by:

Table 2 - Sectoral rate of profit.

\begin{tabular}{|l|c|c|c|}
\hline & Kaldor-Robinson & Neo-Kaleckian & Bhaduri-Marglin \\
\hline Profit Rate & $r_{i}^{*}=\frac{g_{o}}{s_{i}-\alpha}$ & $r_{i}^{*}=\frac{\pi_{i} g_{o}}{\pi_{i}\left(s_{i}-\alpha\right)-\beta}$ & $r_{i}^{*}=\frac{\pi_{i}\left(g_{o}+\alpha \pi_{i}\right)}{s_{i} \pi_{i}-\beta}$ \\
\hline
\end{tabular}

By equalizing these rates of profit with the natural rate of profit from the Pasinettian approach - equation (28) - it is possible to determine in each case the savings rates that would keep the economy in a multi-sector equilibrium. Hence it is possible to determine in each case the saving rates that should be adopted in order to keep each sector in full capacity utilization. In each of these generations this is given by the following table:

Table 3 - Sectoral saving rates.

\begin{tabular}{|c|c|c|c|}
\hline & Kaldor-Robinson & Neo-Kaleckian & Bhaduri-Marglin \\
\hline \multirow{2}{*}{ Saving rates } & $s_{i}=\frac{g_{o}}{n+\theta_{i}}+\alpha$ & $s_{i}=\frac{\beta}{\pi_{i}}+\frac{g_{o}}{n+\theta_{i}}+\alpha$ & $s_{i}=\frac{\beta}{\pi_{i}}+\frac{g_{o}+\alpha \pi_{i}}{n+\theta_{i}}$ \\
\hline
\end{tabular}

The saving rate in the Kaldor-Robinson model has to be given by the expression indicated in the previous table. This is a requirement since the model assumes full employment and full or 'normal' capacity utilization. Note that the Robinson's $(1956,1962)$ concept 
of 'normal' rate of capacity utilization is related to that degree of utilization of productive capacity that producers consider as ideally suited to fulfill demand requirements, which is exactly the same requirement made here. Hence in order to keep the system in its equilibrium position it is necessary that the sectoral saving rates practiced by capitalists must necessarily be the one given by that expression. The view that the degree of utilization of productive capacity relevant to the determination of normal prices and the general rates of profits is the normal, or planned, one is emphasized by Vianello (1989, p. 174). According to him the "normal, or 'planned' degree of utilization of productive capacity is the only one compatible with the conception of normal prices as 'central ones', and the guiding lights for investment decisions". Then, the sectoral saving rates as given by the above table are those that promote the equalisation of demand and supply and therefore the prevalence of normal prices. If the sectoral saving rates are different from the ones in the above table then the natural prices will provide only a gravitational benchmark for real prices.

Accordingly, in the Neo-Kaleckian and the Bhaduri-Marglin versions the savings rates given in the table above are just a normative criterion since these models do not require full capacity utilization. But with this approach it is possible to determine a mark-up rate consistent with the natural rate of profit, a question raised by Taylor (1985, p. 384). This issue was also indicated by Nell (1989, p.163) according to whom "[s]o the problem boils down to finding the determinants of the normal rate of profit. Once this is known, the normal mark-up can be calculated in each industry." Once the natural rate of profit is given then it is possible to establish the normal mark-up for each sector. From the relationships $r_{i}=\pi_{i} u_{i}$ and $\pi_{i}=\frac{\tau_{i}}{1+\tau_{i}}$ and by considering that in equilibrium $u_{i}{ }^{*}=1$ the mark-up in each sector related to the natural rate of profit is:

Table 4 - Sectoral mark-up

\begin{tabular}{|c|c|c|c|}
\hline & Kaldor-Robinson & Neo-Kaleckian & Bhaduri-Marglin \\
\hline Mark-up & $\tau_{i}^{*}=\frac{g+\theta_{i}}{1-\left(g+\theta_{i}\right)}$ & $\tau_{i}^{*}=\frac{\beta\left(g+\theta_{i}\right)}{\left(g+\theta_{i}\right)\left(s_{i}-\alpha-\beta\right)-g_{o}}$ & $\tau_{i}^{*}=\frac{\sqrt{\Delta}-\left(g+\theta_{i}\right)\left(s_{i}-\beta\right)}{2\left[\left(g+\theta_{i}\right)\left(s_{i}-\beta\right)-g_{o}-\alpha\right]}$ \\
\hline
\end{tabular}


where

$$
\Delta=\left(g+\theta_{i}\right)^{2}\left(s_{i}-2 \beta\right)^{2}+4\left[\left(g+\theta_{i}\right)^{2}\left(s_{i}-2 \beta\right)-g_{o}^{i}-\alpha_{i}\right]\left[\left(g+\theta_{i}\right) \beta+g_{o}^{i}\right]
$$

A requirement for a positive mark-up rate is: $r_{i}^{*}=g+\theta_{i}<1$. Expression (29) shows that the mark-up rate in the $i$-th sector is determined by the over-all growth rate of demand for the consumption good of this sector. Taking the derivative of the mark-up in the Kaldor-Robinson in Table 4 in relation to the growth rate of demand allows us to see that:

$$
\frac{\partial \tau_{i}^{*}}{\partial \theta_{i}}=\frac{1}{\left[1-\left(g+\theta_{i}\right)\right]^{2}}>0
$$

From (29) the higher the growth rate of per capita demand for the final good of the $i$-th sector the higher the mark-up rate in this sector. If the growth rate of demand is higher in a specific sector then the mark-up in that sector has to be higher in order to yield a larger profit share that allows capitalists to make larger investments in order to fulfil the demand. An important characteristic of this expression is that the mark-up rate does not depend on any distributive characteristic of the model. This result reinforces the view stressed by Mott (2002, p. 164) that "[t]he Kaleckian long run would like to be the Kaldorian long run, which avoids the Harrod-Domar knife-edge though mark-up variation." Note from Expression (29) that while the knife-edge dilemma cannot be expunged from the PKGM it is possible to establish a mark-up rate which is consistent with the knife-edge equilibrium.

Implicit in our analysis was the assumption that each sector would have a particular profit rate which gives rise to particular growth rates of investment and savings. One could argue that the capitalist economies are characterized by the tendency of levelling between sectoral rates of profit in the lines suggested by Smith. But this is just a tendency that may not be confirmed in the real economies due to a number to barrier to capital flows from one sector to another. The existence of monopoly - or oligopoly - in some sectors may be a good explanation for the existence of a particular rate of profit in that sector. According to Jossa (1989, p. 150), "it seems that 
Kalecki's analysis of the effects of changes in the degree of monopoly upon distribution and the equilibrium of national income is not in harmony with the assumption of a tendency toward a levelling of profit rates in the different departments." In this vein, the previous analysis in which each sector has a particular profit rate still holds in a Kaleckian set up.

\section{Concluding Remarks}

One of the key distinctions between the orthodox view and the Post-Keynesian growth models is the importance given to the supply and demand determination of economic growth. While the later focuses on demand the former stresses the supply side as determinant of the process of economic growth. But this is not the only difference between these two approaches. The dominant neoclassical literature on economic growth is inadequate to deal with the technological issues since its frameworks cannot take into account the complexities of the innovation process and conditions particular to the economies. But what is known as the original PKGM in fact is subject to the same criticism as the Neoclassical model since these models are aggregated in one sector. In the present paper what is being offered is a vision of a canonical Post-Keynesian approach to conceptualizing growth based on the principle of effective demand, with which each individual Post-Keynesian traditions - Kaleckian and Pasinettian - can be shown to be consistent.

One strength of our approach is that we find it possible to determine the natural rate of profit that makes the mark-up rate to be constant over time. In fact, we learn from this analysis that the actual structural dynamics depends ultimately on the distributive features of the economy and not only on the evolution patterns of demand and technological progress as in the Pasinettian view. This is a step further in order to build a unified Post-Keynesian theory of economic growth. Besides, an important improvement that our approach brings to the PKGM is the possibility of considering that different sectors are under different regimes. If one sector is under a 'stagnationist' regime, then an increase in the wage share of the economy as a whole may bring an increase for the demand of the final good produced by that sector. This fact shows that the structural 
economic dynamics is conditioned not only to patterns of evolution of demand and diffusion of technological progress but also on the distributive features of the economy that can give rise to different regimes of economic growth.

\section{References}

ARAUJO, J. The government sector in Kaldor-Pasinetti Models. Journal of Post-Keynesian Economics 15(2), $211-228,1992-93$.

ARAUJO, R. and LIMA, G. A Structural Economic Dynamic Approach to Balance of Payment Constrained Growth. Cambridge Journal of Economics 31(5), 755 - 774, 2007.

ARAUJO, R. and TEIXEIRA, J. Structural change and decisions on investment allocation. Structural Change and Economic Dynamics 13, 249-258, 2002.

BELLINO, E. Employment and income distribution from a Classical-Keynesian viewpoint: some tools to ground a normative analysis. 2010. In E. Brancaccio and G. Fontana (eds.), The Global Economic Crisis: New Perspectives on the Critique of Economic Theory and Policy, Routledge, London, 2011.

BHADURI, A. and MARGLIN, S. Unemployment and the real wage: the economic basis for contesting political ideologies. Cambridge Journal of Economics, 14 (4), 375- 93, 1990.

BLECKER, R. International competition, income distribution and economic growth, Cambridge Journal of Economics, 13, 395-412, 1989.

BLECKER, R. Distribution, demand and growth in neo-Kaleckian macro-models. In: Setterfield, M. (Org.). The Economics of Demand-led Growth: Challenging the Supply-side Vision of the Long Run. Cheltenham, UK; Northampton, MA: Edward Elgar, 129 - 152, 2002.

DUTT, A. Stagnation, income distribution and monopoly power. Cambridge Journal of Economics 8 , $25-40,1984$.

DUTT, A. Alternative closures again: a comment on growth, distribution and inflation. Cambridge Journal of Economics 11, 75 - 82, 1987.

DUTT, A. Growth, distribution and uneven development. Cambridge University Press, Malta, 1990.

EATWELL, J. The long period theory of employment. Cambridge Journal of Economics 7, 269 - 285, 1983.

HALEVI, J. The significance of the theory of vertically integrated processes for the problem of economic development. Structural Change and Economic Dynamics 7, 163 - 171, 1996.

HARCOURT, G. Foreword to the Symposium in Memory of John Cornwall. Review of Political Economy 22, 477-480, 2010.

HARCOURT, G. Foreword. In: Kriesler, Peter. Kalecki's microanalysis: The development of Kalecki's analysis of pricing and distribution. Cambridge: Cambridge Univ Press, 1987.

HARROD, R. International economics. Cambridge, UK: Cambridge University Press.

Jossa, B. 1989. Class Struggle and Income Distribution in Kaleckian Theory. In: Kalecki's Relevance Today. Edited by Mario Sebatiani. Published by the The Macmillan Press Ltd. London, 1933.

KALDOR, N. A model of economic growth. Economic Journal LXVII: 591-624, 1957.

KALECKI, M. Theory of Economic Dynamics: An Essay on Cyclical and Long-Run Changes in Capitalist Economy. London: Allen and Unwin, 1954.

Estud. Econ., São Paulo, vol.45, n.1, p. 127-152, jan.-mar. 2015 
KALECKI, M. The Marxian Equations of Reproduction and Modern Economics. Social Sciences Information 7, $73-79,1968$.

LAVOIE, M. Introduction to Post-Keynesian Economics. Palgrave, MacMillan, 2006.

LAVOIE, M. Kaleckian Effective Demand and Sraffian Normal Prices: Towards a Reconciliation. Review of Political Economy 15(1), 53 - 74, 2003.

LAVOIE, M. Pasinetti's vertically hyper-integrated sectors and natural prices. Cambridge Journal of Economics, 21, 1997.

NELL, E. The Rate of Profit in Kalecki's Theory. In: Kalecki's Relevance Today. Edited by Mario Sebatiani. Published by the Macmillan Press Ltd. London, 1989.

MOTT, T. Longer-run aspects of Kaleckian macroeconomics. In: Setterfield, M. (Org.). The Economics of Demand-led Growth: Challenging the Supply-side Vision of the Long Run. Cheltenham, UK; Northampton, MA: Edward Elgar, 153 - 171, 2002.

OCAMPO, A. The Quest for Dynamic Efficiency. In: Beyond Reforms: Structural Dynamics and Macroeconomic Vulnerability. Edited by José A. Ocampo. Stanford University Press, 2005.

PASINETTI, L. The notion of vertical integration in economic analysis. Metroeconomica, 25, 1 - 29, 1973.

PASINETTI, L. Structural Change and Economic Growth - A Theoretical Essay on the Dynamics of the Wealth of the Nations. Cambridge: Cambridge University Press, 1981.

PASINETTI, L. Growing sub-systems, vertically hyper-integrated sectors and the labour theory of value. Cambridge Journal of Economics, 12, 125 - 34, 1988.

PASINETTI, L. Sraffa's circular process and the concept of vertical integration. In Essays on Pierro Sraffa. Edited by K. Bharadwaj and B. Schefold. London: Unwin Hyman, 1990.

PASINETTI, L. Structural Economic Dynamics - A Theory of the Economic Consequences of Human Learning. Cambridge: Cambridge University Press, 1993.

PASINETTI, L. The Cambridge School of Keynesian Economics. Cambridge Journal of Economics, $29,837-848,2005$.

PASINETTI, L. Keynes and the Cambridge Keynesians: A 'Revolution in Economics'to be Accomplished. Cambridge: Cambridge University Press, 2007.

ROBINSON, J. The Accumulation of Capital. London: Macmillan, 1956.

ROBINSON, J. Essays in the Theory of Economics Growth, London, Macmillan, 1962.

ROWTHORN, R. Demand, Real Wages and Economic Growth, Studi Economici, no. 18, 1982.

SEBASTIANI, M. Introduction: Kalecki's Relevance Today. In: Kalecki's Relevance Today. Edited by Mario Sebatiani. Published by the The Macmillan Press Ltd. London, 1989.

SCAZZIERI, R. Vertical Integration in Economic Theory. Journal of Post Keynesian Economics 13(1), $20-46,1990$.

SMITH, A. An Inquire into the Nature and Causes of the Wealth of Nations. Edited by Campbell R., Skinner, A. and Todd, W., Oxford: Clarendon Press, 1976.

SOLOW, R. A contribution to the theory of economic growth. Quaterly Journal of Economics 70, $65-94,1956$.

SRAFFA, P. Production of Commodities by Means of Commodities. Cambridge University Press, Cambridge, 1960.

STEINDL, J. Maturity and Stagnation in American Capitalism. New York: Monthly Review Press, 1952.

STEEDMAN, I. Questions for Kaleckians. Review of Political Economy 4, 125 - 151, 1992.

STOCKHAMMER, E. Robinsonian and Kaleckian growth. An update on Post-Keynesian growth theories. Working paper no. 67, Vienna University of Economics, Department of Economics, 1999. 
TAYLOR, L. A stagnationist model of economic growth. Cambridge Journal of Economics 9, 383 403, 1985.

THIRLWALL, A. The balance of payments constraint as an explanation of international growth rate differences. Banca Nazionale del Lavoro Quarterly Review, 128, 45 - 53, 1979.

TRIGG, A. and LEE, F. Pasinetti, Keynes and the multiplier, Review of Political Economy, 17(1), $29-43,2005$.

VIANELLO, F. Effective Demand and the Rate of Profits: Some Thoughts on Marx, Kalecki and Sraffa. In: Kalecki's Relevance Today. Edited by Mario Sebatiani. Published by the Macmillan Press Ltd. London, 1989. 